\title{
Modifiable risk factors for patients undergoing lung cancer surgery and their optimization: a review
}

\author{
Sylvain Gagné ${ }^{1}$, Daniel I. McIsaac ${ }^{1,2}$ \\ ${ }^{1}$ Department of Anesthesiology and Pain Medicine, The Ottawa Hospital, University of Ottawa, Ottawa, ON, Canada; ${ }^{2}$ Clinical Epidemiology \\ Program, Ottawa Hospital Research Institute, Ottawa, ON, Canada \\ Contributions: (I) Conception and design: All authors; (II) Administrative support: None; (III) Provision of study materials or patients: None; (IV) \\ Collection and assembly of data: All authors; (V) Data analysis and interpretation: None; (VI) Manuscript writing: All authors; (VII) Final approval of \\ manuscript: All authors. \\ Correspondence to: Sylvain Gagné, MD, FRCPC. Department of Anesthesiology and Pain Medicine, The Ottawa Hospital, University of Ottawa, 501 \\ Smyth Rd., Ottawa, ON K1H 8L6, Canada. Email: sgagne@toh.ca.
}

\begin{abstract}
Enhanced recovery after surgery (ERAS) programs include a variety of pre-, intra- and postoperative interventions that seek to decrease the stress response to surgery and facilitate the recovery of surgical patients. There are a number of patient factors that may increase the risk of postoperative complications (POC) after lung cancer surgery and delay recovery. Some of these factors may be amenable to optimization preoperatively and potentially decrease the incidence of these complications. We have chosen to discuss the incidence and complications associated with factors we felt were both relatively common and significant contributors to POCs. For each of these factors we discuss potential avenues for optimization and the evidence for the resulting decrease in complications.
\end{abstract}

Keywords: Lung; surgery; anesthesia; complications

Submitted Apr 30, 2018. Accepted for publication Oct 05, 2018.

doi: $10.21037 /$ jtd.2018.10.04

View this article at: http://dx.doi.org/10.21037/jtd.2018.10.04

Enhanced recovery after surgery (ERAS) is a multimodal perioperative care pathway designed to achieve early recovery for patients undergoing major surgery (1). A key characteristic of ERAS is that it includes pre-, intra- and post-operative interventions. An extensive evidence base now supports the role of ERAS in decreasing complications and length of stay, and ERAS pathways have been developed and evaluated in most surgical specialties. While general principles, such as avoidance of excess fluid administration and early nutrition and mobilization are common across ERAS pathways for different surgeries, some components are unique to specific surgeries and institutions. Due to the unique characteristics and complication profile of patients having lung surgery, as well as pulmonary physiology, ERAS for lung surgery requires inclusion of unique processes.

Depending on the definitions used and the extent of surgical insult, the risk of postoperative complications (POC) following lung cancer surgery ranges from $6.7 \%$ to $50 \%$ (2), while mortality from lobectomy ranges from $2-4 \%$, sleeve lobectomy $2-11 \%$ and pneumonectomy 6-8\% (3-7). A review by Rotman et al. details the risk of various pulmonary complications after lung cancer surgery. They found that ARDS has an incidence of approximately $5 \%$ after lung resection, persistent air leak ranges from $2-13 \%$, pneumonia $2-22 \%$ and anastomotic dehiscence $6 \%$ (8). Atrial fibrillation has an incidence of $10-20 \%$ after lobectomy and up to $40 \%$ after pneumonectomy (9) and overall cardiac complications $18 \%$ (10). Clearly, with serious complication rates of $5 \%$ to greater than $40 \%$, efforts to decrease adverse postoperative events are required.

To date, numerous ERAS pathways have been described for thoracic surgery. However, a generally agreed upon pathway, or an ERAS society thoracic-specific guideline, have yet to be published (1). A systematic review and metanalysis of randomized controlled trials of enhanced recovery protocols by $\mathrm{Li}$ in 2017 showed that there is 
Table 1 Preoperative risk factors for post-operative complications

\begin{tabular}{ll}
\hline Score/study & Risk factor \\
\hline $\begin{array}{l}\text { Respiratory failure- } \\
\text { Arozullah (15) }\end{array}$ & $\begin{array}{l}\text { Type of surgery, emergency surgery, albumin level less than } 30 \mathrm{~g} / \mathrm{L}, \mathrm{BUN}>10.71 \mathrm{mmol} / \mathrm{L}(30 \mathrm{mg} / \mathrm{dL}), \\
\text { partially of fully dependent functional status, chronic obstructive pulmonary disease (COPD) and age }>60\end{array}$ \\
$\begin{array}{l}\text { Pneumonia-Arozullah (16) } \\
\text { Type of surgery, age, functional status, weight loss, COPD, general anesthesia, impaired sensorium, } \\
\text { cerebral vascular accident, BUN level, transfusion, emergency surgery, long-term steroid use, smoking, } \\
\text { and alcohol use }\end{array}$ & $\begin{array}{l}\text { Age, American Society of Anesthesiologists (ASA) class, COPD, dependent functional status, preoperative } \\
\text { sepsis, smoking before operation, and type of operation }\end{array}$ \\
Pneumonia-Gupta (17) & $\begin{array}{l}\text { Age, sex, functional status, emergency case, ASA class, steroid for chronic condition, ascites, sepsis, } \\
\text { ventilator dependence, disseminated cancer, hypertension, congestive heart failure, dyspnea, current } \\
\text { smoker, history of COPD, dialysis and acute renal failure and diabetes, BMI }\end{array}$ \\
Age, sex, ASA, performance, dyspnea, priority, procedure, diagnosis, comorbidities (smoking addiction, \\
Thoracoscore (18) & $\begin{array}{l}\text { history of cancer, COPD, arterial hypertension, heart disease, diabetes mellitus, peripheral vascular } \\
\text { disease, obesity and alcoholism) }\end{array}$ \\
Age, ppoFEV1
\end{tabular}

BUN, blood urea nitrogen; BMI, body mass index.

substantial variation in the preoperative elements included in thoracic ERAS pathways (11). Those included in the review included one or more of the following: patient education/ counseling, shortened fasting, prophylactic antibiotics, respiratory drug intervention, intensive pulmonary physiologic therapy, physical muscle exercise training, cardiopulmonary exercise testing and optimized diets. Other pathways have also included smoking cessation (12), and optimization of comorbidities (13).

Studies examining the impact of these ERAS pathways in thoracic surgery have yielded inconsistent results, potentially due to variation in pathway design. A systematic review by Fiore in 2016 found no significant difference in rates of complications, mortality or readmissions associated with ERAS (14). However, the overall quality of included studies was poor. Two subsequent retrospective reviews $(10,13)$ did find a decrease in complications and LOS after lung surgery, while a third showed a significantly lower rate of morbidity (11).

To address the variability in thoracic ERAS pathway designs and the resultant outcomes, consideration should be given to the entirety of the perioperative period. However, the first step in successful application of ERAS must be preoperative patient optimization. In particular, preoperative ERAS interventions should include processes that target known risk factors for complications that can be modified in the period between the decision being made to operate and the surgical date; ideally components should have evidence supporting their efficacy or effectiveness.
Fortunately, as detailed in Table 1, many studies are available which identify preoperative risk factors for POCs across all surgeries and some specifically in lung cancer surgery.

Many risk factors that have been identified in lung cancer surgery patients are not modifiable (such as age, sex and cancer severity). However, some potentially modifiable risk factors do exist; appropriate optimization before surgery of such factors could potentially decrease the incidence of POCs and help us achieve our goal of early recovery. Therefore, the objective of this review is to synthesize and describe preoperative components of ERAS pathways that address common and potentially modifiable risk factors for POCs after lung cancer surgery including: anemia, chronic obstructive pulmonary disease (COPD), smoking cessation, malnutrition, alcohol consumption and frailty. While our focus will be on lung cancer, it should be recognized that many of the interventions are applicable to patients having lung surgery for benign reasons, or esophageal surgery, particularly in the presence of similar risk factors. Where evidence is lacking, knowledge gaps and/or emerging strategies will be highlighted. To complete this review a broad online search of the relevant literature was performed using PubMed.

\section{Frailty}

Frailty is a multidimensional syndrome related to age- and disease-related deficits that accumulate across the lifespan $(20,21)$. Due to the accumulation of deficits, people with 
frailty are vulnerable to stressors, and are at increased risk of adverse health outcomes. While data detailing the prevalence of frailty in lung surgery patients is limited, and dependent upon criteria and cut-offs employed, over $30 \%$ of older people having major inpatient surgery live with frailty (22).

Many frailty instruments have been described and studied in the perioperative period (23-25), and almost all are associated with a 2 -fold or greater increase in risk for mortality, POCs, and loss of independence after surgery. The association of frailty with outcomes in thoracic surgery has been reviewed, and overall limited thoracic surgeryspecific data is available (26). These data suggest that frailty may be more strongly associated with adverse outcomes in thoracic surgery than in other specialties (4- to 7-fold increase in odds of adverse events compared to 2- to 3-fold). However, the majority of available data rely upon the National Surgical Quality Improvement Program modified Frailty Index, which has significant issues with missing data and does not align with accepted methods for frailty index development (27).

Due to its multidimensional nature, frailty contributes to adverse outcomes through a variety of mechanisms. Most commonly, cognitive, physiologic, and physical vulnerability contribute to increased rates of delirium (28), complications (29) and higher rates of early mortality (30), and decreased function and need for institutional discharge respectively $(24,31)$. Strategies to prevent postoperative delirium, such as enhanced orientation, maintenance of physiologic homeostasis, and early mobilization should be planned for prior to surgery (32). A growing evidence base suggests that centrally acting medication are unlikely to prevent delirium, and should be reserved for hyperactively delirious individuals who are at risk of causing harm to self or others (33). Exercise and nutritional prehabilitation can both decrease the severity of frailty itself $(34,35)$, and in a low risk of bias randomized trial in major abdominal surgery, personalized exercise and nutritional prehabilitation was efficacious in decreasing complication rates by $31 \%$ (36). Preoperative collaboration with specialists in geriatric medicine is also recommended, and may contribute to improve survival, decreased length of stay, and reduced complication rates $(37,38)$.

Consistent with best practice guidelines for preoperative evaluation of the older surgical patient (39) we recommend routine frailty assessment of older adults prior to thoracic surgery to guide risk communication and to allow for individualized optimization.

\section{Anemia}

Anemia is common in lung cancer surgery patients, with a reported prevalence of $26 \%$ (40). In addition to its high prevalence, anemia is also a risk factor for poor postsurgical outcomes, and is associated with a $2-3$-fold increase in respiratory and infectious complications $(41,42)$. A small study by Anile $e t a l$. found that in patients undergoing lung cancer surgery there was no correlation between anemia and rates of POCs but they did find that those who were anemic had higher rates of blood transfusion which were in turn associated with higher rates of POCs and SSIs (43). Studies also suggest that anemia is associated with decreased mid- and long-term survival $(40,44)$. Debate continues as to whether anemia is a causative factor or a marker for severity of illness, and further research is required to determine whether correcting anemia results in improved outcomes. However, based on postulated pathways, and evidence from other surgical specialties $(45,46)$, it is reasonable to assume that correction of anemia could result in better outcomes in lung surgery patients.

Although anemia can be corrected by transfusion of red blood cells, there is significant evidence to suggest that lung surgery patient (47) and non-lung surgery patients (48-50) who receive a transfusion are at an increased risk of POCs. Typically, transfusions are not recommended above a hemoglobin of $70 \mathrm{~g} / \mathrm{L}$, as increased complications can result from immune modulation, volume overload, transfusion reactions and the debated role of RBC transfusions on cancer recurrence (51-53). For these reasons many have advocated for treating the anemia preoperatively without transfusions. Existing literature suggests that optimizing hemoglobin decreases the need for transfusions in total joint arthroplasty and abdominal surgery $(46,54,55)$, while also decreasing LOS (56). Therefore, the majority of evidence suggests it is reasonable to optimize patients' hemoglobin without transfusing red blood cells (as would their primary care physician) in the limited time available from diagnosis to surgery.

Treatment of anemia starts with identification of the underlying cause. Basic investigations should include complete blood count (CBC), ferritin, transferrin saturation, inflammatory markers (such as C-reactive protein) and renal function. The most common cause of anemia is iron deficiency, however the cancer-related inflammatory state and resultant iron sequestration may also contribute (57).

Multiple modalities exist for correction of preoperative anemia. Fortunately, as most anemia is iron-deficiency 
related, many preoperative anemias will be responsive to iron therapy. Oral iron supplementation can be effective (57), but certain factors limit its preoperative use. These include time to effect and variable absorption and tolerability, which can be made worse by the inflammatory state (58). With an expected time from diagnosis to surgery of less than 4 weeks according to jurisdictional and specialty society guidelines (59) a more viable option is the use of intravenous (IV) iron. With the use of IV iron a maximal response may be seen in 2-3 weeks depending on the dose and type of IV iron (60). If the cause of anemia is iron sequestration one could consider the use of recombinant erythropoietin (rEPO) (57). This is controversial in the setting of lung cancer as rEPO has been linked with an increase in mortality, thrombotic events and worse response to treatment in patients with an active malignancy. A thorough exploration of this issue is available (61). Due to these risks of rEPO in the context of an active malignancy, the American Society of Hematology only recommends $\mathrm{rEPO}$ if the anemia has arisen as a result of concomitantly administered chemotherapy and only to limit the need for transfusion (62). They do not comment on the surgical period. Because of the challenges in establishing the risk benefit ratio to the individual patient, as well as issues of timely access, the assistance of a hematologist or transfusion medicine specialist should be sought if planning the use of IV iron, and in particular rEPO before surgery.

We recommend screening for anemia and optimizing hemoglobin when possible.

\section{Chronic obstructive pulmonary disease (COPD)}

Over $40 \%$ of patients with lung cancer have COPD (63), a diagnosis which is associated with an approximately 3 -fold increase in the rate of complications such as pneumonia and prolonged air leak, and a doubling of the risk of death following lung resection $(64,65)$. Even patients with early or mild COPD face increased risk of adverse outcome (66), however, it is currently unclear the extent to which increasing COPD severity predicts increased risk $(66,67)$.

The Global Initiative for Chronic Obstructive Lung Disease (GOLD) guidelines suggest optimization of COPD management prior to surgery but offer no specific treatment recommendations for the perioperative period (68). The recommendation to optimize appears reasonable given the potential for COPD exacerbations in the postoperative period (69), and some evidence can be extrapolated to support specific strategies for optimization. Such strategies include medical therapy, pulmonary rehabilitation and smoking cessation (which we will cover separately).

The GOLD guidelines published in 2017 describe the approach to medical and non-medical management of COPD. With the diagnosis of COPD patients should begin therapy with an inhaled short acting Beta agonist to be used as needed. With a forced expiratory volume in 1 second (FEV1) $<80 \%$ predicted patients should start using a long acting muscarinic antagonist (LAMA) or long acting beta agonist (LABA) or both based on symptoms (68). The 2017 GOLD guidelines have changed the role of inhaled glucocorticosteroids (ICS) and now reserve these for "patients with a history of exacerbations" despite appropriate treatment with long acting bronchodilators. In terms of perioperative-specific recommendations, the GOLD guideline states that "To prevent postoperative pulmonary complications, stable COPD patients clinically symptomatic and/or with limited exercise capacity should be treated with medically intensively before surgery, with all the measures already well established for stable COPD patients who are not about to have surgery." Other specialty society guidelines, such as the Canadian Thoracic Society, provide no specific recommendations (70), other than to escalate therapy in a stepwise fashion based on symptom control.

Given the limited time to optimize COPD in the preoperative period, it can be difficult to titrate therapy and observe response. There is, however, limited literature to help guide us in the preoperative period. Specifically, patients treated with chronic LAMAs or who start treatment with a LAMA for a new preoperative diagnosis of COPD have improved spirometry results (FVC, FEV1 and therefore predicted postoperative FEV1), symptoms and complications rates (71-73). The duration of therapy required to achieve these results ranged from 1 to 2 weeks. Despite the reduced reliance on ICS in the GOLD and other guidelines, there is some weak evidence suggesting a significant preoperative benefit in terms of decreased PPCs and improved FEV1 with the use of ICS (74). Systemic steroid therapy has also been described, however the evidence supporting this approach is limited and of poor quality (75). Our local approach has been to maximize the use of LAMAs followed by LAMA/LABA combinations and reserve ICSs for patients with very severe airflow restriction or more symptomatic patients with severe airflow restriction. Systemic steroids are usually reserved for patients who may be presenting with an exacerbation or very poorly controlled disease and usually in conjunction with a respirologist. This local approach is detailed in Figure 1. 


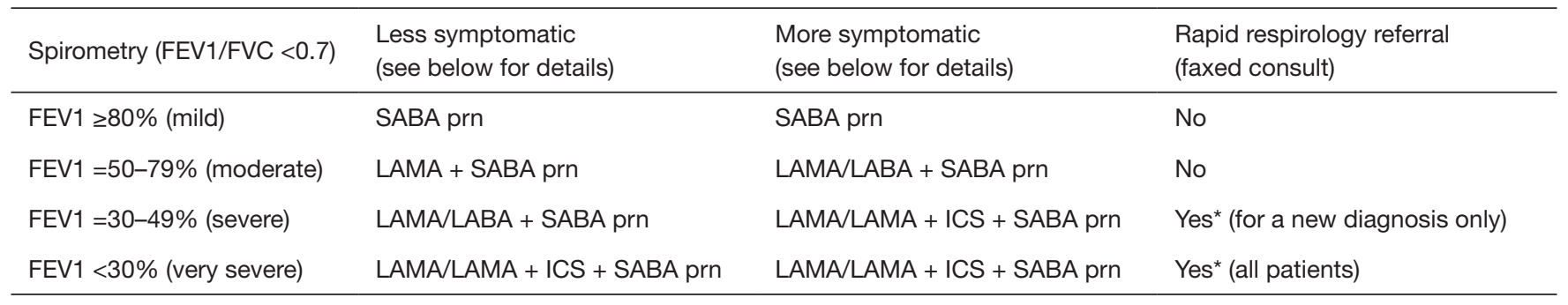

Figure 1 The Ottawa Hospital preoperative COPD optimization protocol (76). *, if the patient's surgery is in <2 weeks please use the inpatient consult service instead. Less symptomatic: no history of exacerbations in the past year (antibiotics, prednisone use, hospitalizations) and MRC dyspnea scale of 1-2; More symptomatic: history of exacerbations in the past year (antibiotics, prednisone use, hospitalizations) and/or MRC of 3-5; MRC dyspnea 3: walks slower than people of the same age on the level because of breathlessness or has to stop for breath when walking at own pace on the level. FEV1, forced expiratory volume in 1 second; FVC, forced vital capacity; SABA, short acting beta agonist; LAMA, long acting muscarinic antagonist; ICS, inhaled corticosteroid; MRC, Medical Research Council dyspnea.

Pulmonary rehabilitation is also recommended. GOLD guidelines recommend incorporating non-pharmacologic interventions such as pulmonary rehabilitation in a COPD management plan (68). Such interventions typically last 6-8 weeks and incorporate patient tailored aerobic, strength and respiratory muscle training. Rehabilitation is likely the most effective therapeutic strategy to improve shortness of breath, health status and exercise tolerance in COPD (77). The preoperative use of this intervention in high risk patients undergoing both abdominal and thoracic surgery significantly decreases postoperative pulmonary complications (PPCs) $(36,78)$. The limitations of this therapy include variable rates of completion by patients, limited access to the required resources and a typically long program duration. Fortunately, there is evidence that shorter courses of prehabilitation are still associated with decreased PPCs. Meta analyses show that inspiratory muscle training was associated with a 50\% decrease in PPCs $(79,80)$. Factors associated with greater success included: supervised programs of at least 2-week duration, with each session lasting more than 15 minutes. Effectiveness was also increased with imposed load increment, and adding other modes of exercise. The possibility of using homebased programs increases the feasibility of this intervention for patients with limited local access to hospital resources. An interesting point to consider is that the improvement in aerobic capacity and spirometry results may change the operability of certain high risk patients based on improved predicted postoperative FEV1 allowing for expanded treatment options (81).

We recommend assessing the presence and severity of COPD followed by rapidly optimizing pharmaceutical therapy and initiating inspiratory muscle training for those at highest risk.

\section{Smoking cessation}

Although smoking cessation is a pillar of COPD management, we have described it separately due to the non-COPD associated impact of perioperative smoking. According to one population-based study, the prevalence of a smoking history in those undergoing surgery for lung cancer is upwards of $85 \%$ (82). This same study suggests that complications rates for current and past smokers is more than doubled that for non-smokers and the hospital mortality rates were almost four times as great. These assertions are supported by other studies $(18,83,84)$, but the literature is not unanimous in these findings (85-87).

Despite the extremely addictive nature of nicotine, a comprehensive intervention defined as an in person intervention with follow up contact combined with nicotine replacement therapy can result in significant quit rates (88). A systematic review and metanalysis by Wong et al. showed that quitting can decrease the risk of wound infections, as well as PPCs (89). The cigarette free period required to impact outcomes would seem to be in the range of 4 weeks for PPCs and 3-4 weeks for wound complications; longer periods are typically associated with better outcomes (89). Interestingly some studies would suggest a benefit simply with abstinence on the day of surgery (90). Studies involving lung cancer surgery, despite showing a decreased complication rate in ex-smokers compared to current smokers, have failed to show the dramatic improvements realized in other types of surgery, unless the smoke free 
period was much longer $(82,91)$. How long that period needs to be remains unclear. In fact a systematic review by Schmidt-Hansen et al. concluded that based on the limited information available they were unable to make firm conclusions regarding smoking cessation prior to lung cancer surgery (92). That is not to say that we should not strive for abstinence in our patients since the benefits of quitting in the long term may be very significant as evidenced by recent data showing a benefit on long term survival in those who quit (93). Furthermore, the noncancer related benefits of smoking cessation cannot be overlooked.

We recommend initiating smoking cessation interventions due to the long-term health benefits of cessation despite the surprising lack of evidence for an acute perioperative impact.

\section{Malnutrition}

The prevalence of malnutrition in thoracic surgery patients varies depending on the definition studied. Less than $5 \%$ of patients are severely underweight, but biomarkers indicating malnutrition are present in up to $40 \%$ of pneumonectomy patients (94-97). Patients with malnutrition have a fourfold higher rate of mortality (98) and complications (94); in particular higher rates of fistula formation (99), discharge to extended care facility (100) and cancer recurrence (101).

Many ERAS society guidelines incorporate some form of nutrition therapy (ERAS) but the evidence for its use in lung cancer surgery is limited. Typically, nutritional therapies can be separated into nutritional support for patients with malnutrition and immunonutrition therapy. Malnourished patients classified as at severe risk using a Nutritional Risk Screening Score (NRS-2002) of 5 or more were found to have a $50 \%$ decrease in post-operative infectious and non-infectious complications when provided with nutritional support for 7 days before abdominal surgery (102). The 2018 American Society for Enhanced Recovery and Perioperative Quality Initiative Joint Consensus Statement on Nutrition Screening and Therapy Within a Surgical Enhanced Recovery Pathway supports screening for malnutrition and treatment of surgical patients (103). However, no specific recommendations for lung cancer patients exist, and our search yielded no trials of therapy aimed at lung cancer surgery patients. Outside of the surgical field, patients with COPD may benefit from nutritional support as peripheral and respiratory muscle function are improved (104). In summary, there appears to be benefit to nutritional support in malnourished patients that may generalize to lung cancer surgery patients. Clinicians should maintain awareness of severely malnourished patients as refeeding syndrome can occur (105).

Immunonutrition, based on the concept that surgical stress leads to a depletion of conditionally essential nutrients and a subsequently dysregulated immune response, involves supplementation with a variety of nutrients, commonly omega-3, arginine, nucleotides, antioxidants and vitamins or minerals (103). The 2018 American Society for Enhanced Recovery and Perioperative Quality Initiative Joint Consensus Statement on Nutrition Screening and Therapy within a Surgical Enhanced Recovery Pathway clearly discusses the limitations of the current literature surrounding immunonutrition. The majority of focus has been in the setting of high-risk gastrointestinal surgery. Current recommendations are to consider immunonutrition, but it is clear that further highquality research is required in this field. There are 2 small positive studies supporting immunonutrition in lung cancer surgery $(106,107)$. A recent metanalysis suggests decreased complications when immunotherapy is used; however, the apparent benefit was lost when analysis was limited to higher quality studies (108).

We recommend nutritional supplementation to all preoperative lung cancer patients with severe malnutrition (NRS-2002 of 5 or greater or equivalent scale). However, we find the evidence for immunonutrition too weak to support this intervention at this time.

\section{Alcohol}

Alcohol use disorder (AUD) is present in $2.5-12 \%$ of lung cancer surgery patients, (109-111) which is similar to the prevalence of AUD in the general population of the United States $(8.25 \%)$. In addition to the multiple comorbidities associated with prolonged excessive alcohol consumption, a metanalysis showed that men who consume more than $36 \mathrm{~g} /$ day (approx. 3 drinks) and women $24 \mathrm{~g} /$ day (approx. 2 drinks) have a $50 \%$ greater risk of POCs (112); a doseresponse relationship also appeared to be present. This may be due to suppression of immune function, increased risk of arrhythmias, impaired hemostasis and exaggerated stress response (113). The findings have been reproduced in patients undergoing lung cancer surgery showing that AUD increased risks of pneumonia by $50 \%$ (110), acute lung injury by $90 \%$ (114) and increased mortality in those consuming at least $60 \mathrm{~g}$ of ETOH per day by $50 \%$ (111). 
The first step addressing AUD is detection. Use of a standardized questionnaire such as the Alcohol Use Disorder Identification Test (AUDIT) can increase detection rates (115), especially if it is embedded in a computer screening tool (116). Once identified, the next goal is decreasing alcohol intake. To date, however, a safe level of preoperative alcohol consumption has not been identified. While total abstinence has been advocated (113), insufficient evidence supports this approach. Realizing the full positive impact of alcohol reduction programs may be a challenge preoperatively, as up to 8 weeks may be required to reverse some of the physiologic effects of alcohol (113). Possible benefits must be weighed against risk of alcohol withdrawal. In some individuals, supervised interventions may be required (113). Overall, limited evidence in the preoperative period suggests that preoperative alcohol cessation interventions do decrease POCs (OR 0.22; 95\% CI, 0.08-0.61). However this metanalysis only included 2 RCTs representing a total of 69 patients (117). Clearly, small studies such as these are at risk of both fragile results and are inadequate to address safety concerns. Planning for postoperative alcohol withdrawal syndrome (AWS) is also required preoperatively, as AWS occurs in $50 \%$ of patients of unrecognized individuals with AUD. Conversely, when AUD is detected and appropriate perioperative measures are taken, AWS occurs in only $25 \%$ of patients with AUD $(111,113)$.

We recommend a decrease in alcohol intake as early as possible prior to surgery. For those at risk of withdrawal we recommend a decrease in ethanol intake and abstinence only if properly supervised.

\section{Conclusions}

Patients undergoing lung surgery for a cancer diagnosis are at a high risk of perioperative complications. While many characteristics that contribute to this high-risk profile are likely not modifiable, certain factors may be amenable to optimization prior to surgery. Early assessment and identification of key risk factors such as frailty, anemia, COPD, smoking, and malnutrition should allow clinicians to engage in rational strategies to improve patients' physical and physiological status before surgery. Because highlevel evidence from low risk of bias randomized trials is not routinely available for these optimization strategies, clinicians are encouraged to weigh the risks and benefits of each strategy at the individual patient level. Future research efforts are urgently required to demonstrate the overall effectiveness of preoperative optimization strategies in thoracic surgery, which should support their routine inclusion in thoracic-specific ERAS protocols.

\section{Acknowledgements}

None.

\section{Footnote}

Conflicts of Interest: The authors have no conflicts of interest to declare.

\section{References}

1. ERAS Society. Available online: http://erassociety.org/

2. Kanzaki R, Inoue $M$, Minami $M$, et al. Outcomes of lung cancer surgery in patients with coronary artery disease: a decade of experience at a single institution. Surg Today 2017;47:27-34.

3. Deslauriers J, Ginsberg RJ, Piantadosi S, et al. Prospective assessment of 30-day operative morbidity for surgical resections in lung cancer. Chest 1994;106:329S-30S.

4. Pierce RJ, Copland JM, Sharpe K, et al. Preoperative risk evaluation for lung cancer resection: predicted postoperative product as a predictor of surgical mortality. Am J Respir Crit Care Med 1994;150:947-55.

5. Naunheim KS, Kesler KA, D’Orazio SA, et al. Lung cancer surgery in the octogenarian. Eur J Cardiothorac Surg 1994;8:453-6.

6. Au J, el-Oakley R, Cameron EW. Pneumonectomy for bronchogenic carcinoma in the elderly. Eur J Cardiothorac Surg 1994;8:247-50.

7. Pagni S, Federico JA, Ponn RB. Pulmonary resection for lung cancer in octogenarians. Ann Thorac Surg 1997;63:785-9.

8. Rotman JA, Plodkowski AJ, Hayes SA, et al. Postoperative complications after thoracic surgery for lung cancer. Clin Imaging 2015;39:735-49.

9. De Decker K, Jorens PG, Van Schil P. Cardiac complications after noncardiac thoracic surgery: an evidence-based current review. Ann Thorac Surg 2003;75:1340-8.

10. Van Haren RM, Mehran RJ, Correa AM, et al. Enhanced Recovery Decreases Pulmonary and Cardiac Complications Following Thoracotomy for Lung Cancer. Ann Thorac Surg 2018;106:272-9.

11. Li S, Zhou K, Che G, et al. Enhanced recovery programs 
in lung cancer surgery: systematic review and metaanalysis of randomized controlled trials. Cancer Manag Res 2017;9:657-70.

12. Loop T. Fast track in thoracic surgery and anaesthesia: update of concepts. Curr Opin Anaesthesiol 2016;29:20-5.

13. Madani A, Fiore JF, Wang Y, et al. An enhanced recovery pathway reduces duration of stay and complications after open pulmonary lobectomy. Surgery 2015;158:899-908; discussion 908-10.

14. Fiore JF, Bejjani J, Conrad K, et al. Systematic review of the influence of enhanced recovery pathways in elective lung resection. J Thorac Cardiovasc Surg 2016;151:708-15.e6.

15. Arozullah AM, Daley J, Henderson WG, et al. Multifactorial risk index for predicting postoperative respiratory failure in men after major noncardiac surgery. The National Veterans Administration Surgical Quality Improvement Program. Ann Surg 2000;232:242-53.

16. Arozullah AM, Khuri SF, Henderson WG, et al. Development and validation of a multifactorial risk index for predicting postoperative pneumonia after major noncardiac surgery. Ann Intern Med 2001;135:847-57.

17. Gupta H, Gupta PK, Schuller D, et al. Development and Validation of a Risk Calculator for Predicting Postoperative Pneumonia. Mayo Clin Proc 2013;88:1241-9.

18. Falcoz PE, Conti M, Brouchet L, et al. The Thoracic Surgery Scoring System (Thoracoscore): Risk model for in-hospital death in 15,183 patients requiring thoracic surgery. J Thorac Cardiovasc Surg 2007;133:325-32.

19. Berrisford R, Brunelli A, Rocco G, et al. The European Thoracic Surgery Database project: modelling the risk of in-hospital death following lung resection. Eur J Cardiothorac Surg 2005;28:306-11.

20. Fried LP, Ferruci L, Darer J, et al. Untangling the concepts of disability, frailty and comorbidity: Implications for improved targeting and care. J Gerontol A Biol Sci Med Sci 2004;59:255-63.

21. Rockwood K, Song X, MacKnight C, et al. A global clinical measure of fitness and frailty in elderly people. CMAJ 2005; 173:489-95.

22. McIsaac DI, Wong CA, Huang A, et al. Derivation and Validation of a Generalizable Preoperative Frailty Index Using Population-based Health Administrative Data. Ann Surg 2018. [Epub ahead of print]

23. Beggs T, Sepehri A, Szwajcer A, et al. Frailty and perioperative outcomes: a narrative review. Can J Anaesth 2015;62:143-57.

24. Kim DH, Kim CA, Placide S, et al. Preoperative Frailty Assessment and Outcomes at 6 Months or Later in Older
Adults Undergoing Cardiac Surgical Procedures. Ann Intern Med 2016;165:650-60.

25. Lin HS, Watts JN, Peel NM, et al. Frailty and postoperative outcomes in older surgical patients: a systematic review. BMC Geriatr 2016;16:157.

26. Dunne MJ, Abah U, Scarci M. Frailty assessment in thoracic surgery. Interact Cardiovasc Thorac Surg 2014;18:667-70.

27. Searle SD, Mitnitski A, Gahbauer EA, et al. A standard procedure for creating a frailty index. BMC Geriatr $2008 ; 8: 24$.

28. Watt J, Tricco AC, Talbot-Hamon C, et al. Identifying Older Adults at Risk of Delirium Following Elective Surgery: A Systematic Review and Meta-Analysis. J Gen Intern Med 2018;33:500-9.

29. Watt J, Tricco AC, Talbot-Hamon C, et al. Identifying older adults at risk of harm following elective surgery: a systematic review and meta-analysis. BMC Med 2018;16:2.

30. McIsaac DI, Bryson GL, van Walraven C. Association of Frailty and 1-Year Postoperative Mortality Following Major Elective Noncardiac Surgery. JAMA Surg 2016;151:538-45.

31. McIsaac DI, Beaule PE, Bryson GL, et al. The impact of frailty on outcomes and healthcare resource utilization after total joint arthroplasty: a population-based cohort study. Bone Joint J 2016;98-B:799-805.

32. Chen CC, Chen CN, Lai IR, et al. Effects of a modified Hospital Elder Life Program on frailty in individuals undergoing major elective abdominal surgery. J Am Geriatr Soc 2014;62:261-8.

33. Delirium: prevention, diagnosis and management. Manchester, UK; 2010.

34. Theou O, Stathokostas L, Roland KP, et al. The effectiveness of exercise interventions for the management of frailty: a systematic review. J Aging Res 2011;2011:569194.

35. Partridge JSL, Harari D, Dhesi JK. Frailty in the older surgical patient: a review. Age Ageing 2012;41:142-7.

36. Barberan-Garcia A, Ubré $M$, Roca J, et al. Personalised Prehabilitation in High-risk Patients Undergoing Elective Major Abdominal Surgery: A Randomized Blinded Controlled Trial. Ann Surg 2018;267:50-6.

37. McIsaac DI, Huang A, Wong CA, et al. Effect of Preoperative Geriatric Evaluation on Outcomes After Elective Surgery: A Population-Based Study. J Am Geriatr Soc 2017;65:2665-72.

38. Partridge JSL, Harari D, Martin FC, et al. The impact of pre-operative comprehensive geriatric assessment on 
postoperative outcomes in older patients undergoing scheduled surgery: A systematic review. Anaesthesia 2014;69:8-16.

39. Chow WB, Rosenthal RA, Merkow RP, et al. Optimal preoperative assessment of the geriatric surgical patient: a best practices guideline from the American College of Surgeons National Surgical Quality Improvement Program and the American Geriatrics Society. J Am Coll Surg 2012;215:453-66.

40. Chamogeorgakis T, Anagnostopoulos C, Kostopanagiotou G, et al. Does Anemia Affect Outcome after Lobectomy or Pneumonectomy in Early Stage Lung Cancer Patients Who Have not Received Neo-Adjuvant Treatment? Thorac Cardiovasc Surg 2008;56:148-53.

41. Fernandes EO, Teixeira C, da Silva LC. Thoracic surgery: risk factors for postoperative complications of lung resection. Rev Assoc Med Bras 2011;57:292-8.

42. Jean RA, DeLuzio MR, Kraev AI, et al. Analyzing Risk Factors for Morbidity and Mortality after Lung Resection for Lung Cancer Using the NSQIP Database. J Am Coll Surg 2016;222:992-1000.e1.

43. Anile M, Venuta F, Diso D, et al. Preoperative anaemia does not affect the early postoperative outcome in patients with lung cancer. Minerva Chir 2007;62:431-5.

44. Yovino S, Kwok Y, Krasna M, et al. An association between preoperative anemia and decreased survival in early-stage non-small-cell lung cancer patients treated with surgery alone. Int J Radiat Oncol Biol Phys 2005;62:1438-43.

45. Steuber TD, Howard ML, Nisly SA. Strategies for the Management of Postoperative Anemia in Elective Orthopedic Surgery. Ann Pharmacother 2016;50:578-85.

46. Calleja JL, Delgado S, del Val A, et al. Ferric carboxymaltose reduces transfusions and hospital stay in patients with colon cancer and anemia. Int J Colorectal Dis 2016;31:543-51.

47. Ferraris VA, Davenport DL, Saha SP, et al. Intraoperative Transfusion of Small Amounts of Blood Heralds Worse Postoperative Outcome in Patients Having Noncardiac Thoracic Operations. Ann Thorac Surg 2011;91:1674-80.

48. Glance LG, Dick AW, Mukamel DB, et al. Association between Intraoperative Blood Transfusion and Mortality and Morbidity in Patients Undergoing Noncardiac Surgery. Anesthesiology 2011;114:283-92.

49. Wu WC, Trivedi A, Friedmann PD, et al. Association Between Hospital Intraoperative Blood Transfusion Practices for Surgical Blood Loss and Hospital Surgical Mortality Rates. Ann Surg 2012;255:708-14.

50. Ferraris VA, Davenport DL, Saha SP, et al. Surgical
Outcomes and Transfusion of Minimal Amounts of Blood in the Operating Room. Arch Surg 2012;147:49.

51. Churchhouse AM, Mathews TJ, McBride OMB, et al. Does blood transfusion increase the chance of recurrence in patients undergoing surgery for lung cancer? Interact Cardiovasc Thorac Surg 2012;14:85-90.

52. Refaai MA, Blumberg N. The transfusion dilemma Weighing the known and newly proposed risks of blood transfusions against the uncertain benefits. Best Pract Res Clin Anaesthesiol 2013;27:17-35.

53. Wang T, Luo L, Huang H, et al. Perioperative Blood Transfusion Is Associated With Worse Clinical Outcomes in Resected Lung Cancer. Ann Thorac Surg 2014;97:1827-37.

54. Theusinger OM, Leyvraz PF, Schanz U, et al. Treatment of Iron Deficiency Anemia in Orthopedic Surgery with Intravenous Iron: Efficacy and Limits. Anesthesiology 2007;107:923-7.

55. $\mathrm{Ng} \mathrm{O}$, Keeler BD, Mishra A, et al. Iron therapy for pre-operative anaemia. Cochrane Database Syst Rev 2015;(12):CD011588.

56. Froessler B, Palm P, Weber I, et al. The Important Role for Intravenous Iron in Perioperative Patient Blood Management in Major Abdominal Surgery: A Randomized Controlled Trial. Ann Surg 2016;264:41-6.

57. Muñoz M, Acheson AG, Auerbach M, et al. International consensus statement on the peri-operative management of anaemia and iron deficiency. Anaesthesia 2017;72:233-47.

58. Pratt JJ, Khan KS. Non-anaemic iron deficiency - a disease looking for recognition of diagnosis: a systematic review. Eur J Haematol 2016;96:618-28.

59. BTS recommendations to respiratory physicians for organising the care of patients with lung cancer. The Lung Cancer Working Party of the British Thoracic Society Standards of Care Committee. Thorax 1998;53 Suppl 1:S1-8.

60. Goodnough LT, Skikne B, Brugnara C. Erythropoietin, iron, and erythropoiesis. Blood 2000;96:823-33.

61. Erythropoiesis-stimulating agents (epoetin and darbepoetin) for treating anaemia in people with cancer having chemotherapy I Guidance and guidelines I NICE. Available online: https://www.nice.org.uk/guidance/ta323

62. Rizzo JD, Brouwers M, Hurley P, et al. American Society of Hematology/American Society of Clinical Oncology clinical practice guideline update on the use of epoetin and darbepoetin in adult patients with cancer. Blood 2010;116:4045-59.

63. Grose D, Morrison DS, Devereux G, et al. Comorbidities 
in lung cancer: prevalence, severity and links with socioeconomic status and treatment. Postgrad Med J 2014;90:305-10.

64. Takegahara K, Usuda J, Inoue T, et al. Preoperative management using inhalation therapy for pulmonary complications in lung cancer patients with chronic obstructive pulmonary disease. Gen Thorac Cardiovasc Surg 2017;65:388-91.

65. Licker MJ, Widikker I, Robert J, et al. Operative mortality and respiratory complications after lung resection for cancer: impact of chronic obstructive pulmonary disease and time trends. Ann Thorac Surg 2006;81:1830-7.

66. Kim ES, Kim YT, Kang CH, et al. Prevalence of and risk factors for postoperative pulmonary complications after lung cancer surgery in patients with early-stage COPD. Int J Chron Obstruct Pulmon Dis 2016;11:1317.

67. Kim HJ, Lee J, Park YS, et al. Impact of GOLD groups of chronic pulmonary obstructive disease on surgical complications. Int J Chron Obstruct Pulmon Dis 2016;11:281-7.

68. From the Global Strategy for the Diagnosis, Management and Prevention of COPD, Global Initiative for Chronic Obstructive Lung Disease (GOLD) 2017. Available online: http://goldcopd.org

69. Leo F, Venissac N, Pop D, et al. Postoperative exacerbation of chronic obstructive pulmonary disease. Does it exist? Eur J Cardiothorac Surg 2008;33:424-9.

70. Bourbeau J, Bhutani M, Hernandez P, et al. CTS position statement: Pharmacotherapy in patients with COPD-An update. Can J Respir Crit Care, Sleep Med 2017;1:222-41.

71. Kobayashi S, Suzuki S, Niikawa H, et al. Preoperative use of inhaled tiotropium in lung cancer patients with untreated COPD. Respirology 2009;14:675-9.

72. Suzuki H, Sekine Y, Yoshida S, et al. Efficacy of perioperative administration of long-acting bronchodilator on postoperative pulmonary function and quality of life in lung cancer patients with chronic obstructive pulmonary disease. Preliminary results of a randomized control study. Surg Today 2010;40:923-30.

73. Nojiri T, Inoue M, Yamamoto K, et al. Inhaled tiotropium to prevent postoperative cardiopulmonary complications in patients with newly diagnosed chronic obstructive pulmonary disease requiring lung cancer surgery. Surg Today 2014;44:285-90.

74. Bölükbas S, Eberlein M, Eckhoff J, et al. Short-term effects of inhalative tiotropium/formoterol/budenoside versus tiotropium/formoterol in patients with newly diagnosed chronic obstructive pulmonary disease requiring surgery for lung cancer: a prospective randomized trial. Eur J Cardiothorac Surg 2011;39:995-1000.

75. Lee HW, Lee JK, Oh SH, et al. Effect of perioperative systemic steroid treatment on patients with obstructive lung disease undergoing elective abdominal surgery. Clin Respir J 2018;12:227-33.

76. Fletcher CM, Elmes PC, Fairbairn AS, et al. The significance of respiratory symptoms and the diagnosis of chronic bronchitis in a working population. Br Med J 1959;2:257-66.

77. McCarthy B, Casey D, Devane D, et al. Pulmonary rehabilitation for chronic obstructive pulmonary disease. Cochrane Database Syst Rev 2015;(2):CD003793.

78. Lai Y, Su J, Qiu P, et al. Systematic short-term pulmonary rehabilitation before lung cancer lobectomy: a randomized trial. Interact Cardiovasc Thorac Surg 2017;25:476-83.

79. Kendall F, Oliveira J, Peleteiro B, et al. Inspiratory muscle training is effective to reduce postoperative pulmonary complications and length of hospital stay: a systematic review and meta-analysis. Disabil Rehabil 2018;40:864-82.

80. Mans CM, Reeve JC, Elkins MR. Postoperative outcomes following preoperative inspiratory muscle training in patients undergoing cardiothoracic or upper abdominal surgery: a systematic review and meta analysis. Clin Rehabil 2015;29:426-38.

81. Mujovic N, Mujovic N, Subotic D, et al. Preoperative pulmonary rehabilitation in patients with non-small cell lung cancer and chronic obstructive pulmonary disease. Arch Med Sci 2014;10:68-75.

82. Mason DP, Subramanian S, Nowicki ER, et al. Impact of Smoking Cessation Before Resection of Lung Cancer: A Society of Thoracic Surgeons General Thoracic Surgery Database Study. Ann Thorac Surg 2009;88:362-70; discussion 370-1.

83. Gajdos C, Hawn MT, Campagna EJ, et al. Adverse Effects of Smoking on Postoperative Outcomes in Cancer Patients. Ann Surg Oncol 2012;19:1430-8.

84. Ogawa F, Wang G, Matsui Y, et al. Risk factors for postoperative complications in the elderly with lung cancer. Asian Cardiovasc Thorac Ann 2013;21:313-8.

85. Seok Y, Hong N, Lee E. Impact of smoking history on postoperative pulmonary complications: a review of recent lung cancer patients. Ann Thorac Cardiovasc Surg 2014;20:123-8.

86. Shimizu K, Nakata M, Hirami Y, et al. Recent results regarding the clinical impact of smoking history on postoperative complications in lung cancer patients. Interact Cardiovasc Thorac Surg 2008;7:1001-6. 
87. Musallam KM, Rosendaal FR, Zaatari G, et al. Smoking and the risk of mortality and vascular and respiratory events in patients undergoing major surgery. JAMA Surg 2013;148:755-62.

88. Thomsen T, Villebro N, Møller AM. Interventions for preoperative smoking cessation. Cochrane Database Syst Rev 2014;(3):CD002294.

89. Wong J, Lam DP, Abrishami A, et al. Short-term preoperative smoking cessation and postoperative complications: a systematic review and meta-analysis. Can J Anaesth 2012;59:268-79.

90. Nolan MB, Martin DP, Thompson R, et al. Association Between Smoking Status, Preoperative Exhaled Carbon Monoxide Levels, and Postoperative Surgical Site Infection in Patients Undergoing Elective Surgery. JAMA Surg 2017;152:476-83.

91. Lugg ST, Tikka T, Agostini PJ, et al. Smoking and timing of cessation on postoperative pulmonary complications after curative-intent lung cancer surgery. J Cardiothorac Surg 2017;12:52.

92. Schmidt-Hansen M, Page R, Hasler E. The Effect of Preoperative Smoking Cessation or Preoperative Pulmonary Rehabilitation on Outcomes After Lung Cancer Surgery: A Systematic Review. Clin Lung Cancer 2013;14:96-102.

93. Dobson Amato KA, Hyland A, Reed R, et al. Tobacco Cessation May Improve Lung Cancer Patient Survival. J Thorac Oncol 2015;10:1014-9.

94. Thomas PA, Berbis J, Falcoz PE, et al. National perioperative outcomes of pulmonary lobectomy for cancer: the influence of nutritional status. Eur J Cardiothorac Surg 2014;45:652-9.

95. Bagan P, Berna P, De Dominicis F, et al. Nutritional Status and Postoperative Outcome After Pneumonectomy for Lung Cancer. Ann Thorac Surg 2013;95:392-6.

96. Trufă DI, Arhire LI, Niţă O, et al. The evaluation of preoperative nutritional status in patients undergoing thoracic surgery. Rev Med Chir Soc Med Nat Iasi 2014;118:514-9.

97. Zhang L, Wang C, Sha SY, et al. Mini-nutrition assessment, malnutrition, and postoperative complications in elderly Chinese patients with lung cancer. J BUON 2012;17:323-6.

98. Fiorelli A, Vicidomini G, Mazzella A, et al. The Influence of Body Mass Index and Weight Loss on Outcome of Elderly Patients Undergoing Lung Cancer Resection. Thorac Cardiovasc Surg 2014;62:578-87.

99. Matsuoka K, Misaki N, Sumitomo S. Preoperative hypoalbuminemia is a risk factor for late bronchopleural fistula after pneumonectomy. Ann Thorac Cardiovasc Surg 2010;16:401-5.

100. Walters DM, Nagji AS, Stukenborg GJ, et al. Predictors of Hospital Discharge to an Extended Care Facility after Major General Thoracic Surgery. Am Surg 2014;80:284-9.

101. Kawai H, Ota H. Low Perioperative Serum Prealbumin Predicts Early Recurrence after Curative Pulmonary Resection for Non-Small-Cell Lung Cancer. World J Surg 2012;36:2853-7.

102. Jie B, Jiang ZM, Nolan MT, et al. Impact of preoperative nutritional support on clinical outcome in abdominal surgical patients at nutritional risk. Nutrition 2012;28:1022-7.

103. Wischmeyer PE, Carli F, Evans DC, et al. American Society for Enhanced Recovery and Perioperative Quality Initiative Joint Consensus Statement on Nutrition Screening and Therapy Within a Surgical Enhanced Recovery Pathway. Anesth Analg 2018;126:1883-95.

104. Whittaker JS, Ryan CF, Buckley PA, et al. The Effects of Refeeding on Peripheral and Respiratory Muscle Function in Malnourished Chronic Obstructive Pulmonary Disease Patients. Am Rev Respir Dis 1990;142:283-8.

105.Mehanna HM, Moledina J, Travis J. Refeeding syndrome: what it is, and how to prevent and treat it. BMJ 2008;336:1495-8.

106. Matzi V, Lindenmann J, Muench A, et al. The impact of preoperative micronutrient supplementation in lung surgery. A prospective randomized trial of oral supplementation of combined $\alpha$-ketoglutaric acid and 5-hydroxymethylfurfural. Eur J Cardiothorac Surg 2007;32:776-82.

107. Kaya SO, Akcam TI, Ceylan KC, et al. Is preoperative protein-rich nutrition effective on postoperative outcome in non-small cell lung cancer surgery? A prospective randomized study. J Cardiothorac Surg 2016;11:14.

108. Probst P, Ohmann S, Klaiber U, et al. Meta-analysis of immunonutrition in major abdominal surgery. Br J Surg 2017;104:1594-608.

109. Neuenschwander AU, Pedersen JH, Krasnik M, et al. Impaired postoperative outcome in chronic alcohol abusers after curative resection for lung cancer. Eur J Cardiothorac Surg 2002;22:287-91.

110.Simonsen DF, Søgaard M, Bozi I, et al. Risk factors for postoperative pneumonia after lung cancer surgery and impact of pneumonia on survival. Respir Med 2015;109:1340-6.

111. Green A, Hauge J, Iachina M, et al. The mortality 
after surgery in primary lung cancer: results from the Danish Lung Cancer Registry. Eur J Cardiothorac Surg 2016;49:589-94.

112.Eliasen M, Grønkjær M, Skov-Ettrup LS, et al.

Preoperative Alcohol Consumption and Postoperative Complications: A Systematic Review and Meta-analysis. Ann Surg 2013;258:930-42.

113. Tønnesen H, Nielsen PR, Lauritzen JB, et al. Smoking and alcohol intervention before surgery: evidence for best practice. Br J Anaesth 2009;102:297-306.

114.Licker M, Perrot M de, Spiliopoulos A, et al. Risk Factors for Acute Lung Injury After Thoracic Surgery for Lung

Cite this article as: Gagné S, McIsaac DI. Modifiable risk factors for patients undergoing lung cancer surgery and their optimization: a review. J Thorac Dis 2018;10(Suppl 32):S3761S3772. doi: $10.21037 /$ jtd.2018.10.04
Cancer. Anesth Analg 2003;97:1558-65.

115.Kork F, Neumann T, Spies C. Perioperative management of patients with alcohol, tobacco and drug dependency. Curr Opin Anaesthesiol 2010;23:384-90.

116.Kip MJ, Neumann T, Jugel C, et al. New Strategies to Detect Alcohol Use Disorders in the Preoperative Assessment Clinic of a German University Hospital. Anesthesiology 2008;109:171-9.

117. Oppedal K, Møller AM, Pedersen B, et al. Preoperative alcohol cessation prior to elective surgery. Cochrane Database Syst Rev 2012;(7):CD008343. 